\title{
Wind Induced Vibration Control and Energy Harvesting of Electromagnetic Resonant Shunt Tuned Mass-Damper-Inerter for Building Structures
}

\author{
Yifan Luo, ${ }^{1}$ Hongxin Sun, ${ }^{1,2}$ Xiuyong Wang, ${ }^{1}$ Lei Zuo, ${ }^{2}$ and Ning Chen ${ }^{1}$ \\ ${ }^{1}$ School of Civil Engineering, Hunan University of Science and Technology, Xiangtan 411201, China \\ ${ }^{2}$ Department of Mechanical Engineering, Virginia Tech, Blacksburg, VA, USA \\ Correspondence should be addressed to Hongxin Sun; cehxsun@hnust.edu.cn
}

Received 20 February 2017; Accepted 24 April 2017; Published 13 July 2017

Academic Editor: Sundararajan Natarajan

Copyright (c) 2017 Yifan Luo et al. This is an open access article distributed under the Creative Commons Attribution License, which permits unrestricted use, distribution, and reproduction in any medium, provided the original work is properly cited.

\begin{abstract}
This paper proposes a novel inerter-based dynamic vibration absorber, namely, electromagnetic resonant shunt tuned massdamper-inerter (ERS-TMDI). To obtain the performances of the ERS-TMDI, the combined ERS-TMDI and a single degree of freedom system are introduced. $\mathrm{H}_{2}$ criteria performances of the ERS-TMDI are introduced in comparison with the classical tuned mass-damper (TMD), the electromagnetic resonant shunt series TMDs (ERS-TMDs), and series-type double-mass TMDs with the aim to minimize structure damage and simultaneously harvest energy under random wind excitation. The closed form solutions, including the mechanical tuning ratio, the electrical damping ratio, the electrical tuning ratio, and the electromagnetic mechanical coupling coefficient, are obtained. It is shown that the ERS-TMDI is superior to the classical TMD, ERS-TMDs, and series-type double-mass TMDs systems for protection from structure damage. Meanwhile, in the time domain, a case study of Taipei 101 tower is presented to demonstrate the dual functions of vibration suppression and energy harvesting based on the simulation fluctuating wind series, which is generated by the inverse fast Fourier transform method. The effectiveness and robustness of ERS-TMDI in the frequency and time domain are illustrated.
\end{abstract}

\section{Introduction}

It is a well-known fact that protecting structures against dynamic loads such as winds and earthquakes has been one of the chief purposes in structural design. Many research has been conducted to search for complementary energy dissipation devices to suppress the harmful oscillation. Among these methods, the classical tuned mass-damper (TMD) [1], as dynamic vibration absorber, has been proved to be one of the most effective and popular supplemental energy dissipation devices [2-5], with many pragmatic installations [6-8].

Later on, various methods to optimize the parameters of TMD have been developed. For the TMD with undamped primary systems, there are some common methods, such as fixed-point method, $H_{2}$ norm, and $H_{\infty}$ optimal method. For the TMD with damped primary systems, substantive design methods and tuning criteria have been raised [9], and the
TMD applied in nonlinear and distributed primary systems has been studied [10, 11].

Meanwhile, energy harvesting from large-amplitude lowfrequency oscillating primary structures has emerged as a promising research area $[12,13]$, especially from TMD [1419]. It depends on replacing the energy-dissipating element of the TMD or supplementing with electromagnetic harvester, for relatively large-scale applications [14-18], or piezoelectric materials, even for relatively small-scale applications $[17,19]$. Under this background, a concept of tuned massdamper/harvester $(\mathrm{TMD} / \mathrm{H})$ is presented in [20], in which the basic conversion consists of a linear voice coil motor connected to a resistance emulator consisting of rectification and variable impedance unit. Along a similar path, an electromagnetic transducer connected with an energy harvestingenabled circuit is used to transform vibration energy into electric power and also to supply controlled force vibrations 
mitigation for TMD-equipped multilayer buildings structures in [11]. In addition, Ali and Adhikari proposed the idea of an energy harvester dynamic vibration absorber (EHDVA) [19], in which electric energy is generated from strains developed in layers of piezoelectric material with the electric circuit mounted onto the attached vibrating mass of a TMD. They also provided an analytical derivation of the EH-DVA under harmonic and random excitation $[19,21]$.

Lately, an inerter, a two-terminal mechanical device, is proposed by Smith et al. $[22,23]$. The inerter is a device that provides a force proportional to the relative acceleration between its two terminals. Moreover, the inerter has been studied for improvement of car suspensions [24-26] and railway vehicles $[27,28]$. Other applications of inerters can also be found in civil engineering for improving the performance of vibration control and displacement mitigation in base isolation systems. It was proposed the idea of using an inerter-like ball-screw mechanism to be employed in a viscous mass-damper or tuned viscous mass-damper system in [29]. A type of electromagnetic inertial mass-damper using a ball-screw mechanism and a motor was presented to control the vibration of structures subjected to earthquakes in [30]. Moreover, an inertia-based passive control based on a gyro-mass-damper using gear assemblies was also studied as a type of supplemental damper [31] and as a base isolation system [32]. Lazar et al. [33, 34] proposed an inerter-based system with a configuration similar to that of a TMD, which is termed as tuned inerter damper (TID) and developed an analytical tuning rule of a TID based on the Den Hartog's method. Marian and Giaralis [35] also proposed the concept of tuned mass-damper-inerter (TMDI) to mitigate the oscillatory motion of support systems which are stochastically excited. They also developed the optimal TMDI parameters for undamped primary structures under white noise excitation in closed-form as functions of the TMD mass and the inertance. Further, they proposed the energy harvesting-enabled tuned mass-damper-inerter (EHTMDI) configuration for simultaneous vibration suppression and energy harvesting [36].

Inspired by the idea of EH-TMDI [35, 36], this paper proposes a novel inerter-based dynamic vibration absorber, called electromagnetic resonant shunt tuned mass-damperinerter (ERS-TMDI), in which we replace the dissipated element of the TMDI with the electromagnetic transducer shunted with a resonant R-L-C circuit for simultaneous vibration control and energy harvesting. In addition, this paper derives the closed-form solution of optimal design parameters to the ERS-TMDI for building structures under random wind and presented numerical analyses. $H_{2}$ norm optimal method is employed for the undamped single degree of freedom (SDOF) structure, with the objective to minimize the mean squared value of the displacement of the primary structure. The advantages of the ERS-TMDI will be illustrated through the comparison with the classical TMD, series-type double-mass TMDs [37], and ERS-TMDs [38].

The remainder of this paper is organized as follows. In Section 2, the governing equations of the SDOF system with ERS-TMDI are derived. Section 3 derives optimal $\mathrm{H}_{2}$ closed-form solutions to the ERS-TMDI systems under the wind force excitation. In Section 4, the numerical analysis of structures is presented in comparison with the classical TMD and ERS-TMDs. Conclusions are drawn in Section 5.

\section{The Single Degree of Freedom System Model of the Electromagnetic Resonant Shunt Tuned Mass-Damper-Inerter}

As is shown in Figure 1(a), for easily understanding the reduction effects of the damper, a multistory building is simplified as a general multidegree of freedom (MDOF) system. Further, Figure 1(a) also shows the configuration of ERS-TMDI for the MDOF, where the ERS-TMDI is obtained by replacing the original energy dissipative damping $c_{T}$ in classical TMD with an electromagnetic transducer shunted with a resistance $R$, capacitance $C$, and inductance $L[16,39]$, and an inertance $b$, a two-terminal mechanical device, is assigned between the absorber and next story of structure, for simultaneous vibration control and energy harvesting under the force excitation of the primary structure.

When multistory buildings are subjected to wind vibration, the first-order modal played a very important role in the analysis of vibration. Therefore, the primary structure is characterized as single degree of freedom (SDOF) structure with a linear spring of stiffness $k_{s}$, a mass $m_{s}$, and a damping coefficient $c_{s}$, as shown in Figure 1(b).

The motion equations of the combined SDOF and ERSTMDI system, shown in Figure 1(b), can be given by

$$
\begin{array}{r}
m_{s} \ddot{x}_{s}+c_{s} \dot{x}_{s}+k_{s} x_{s}-k_{T}\left(x_{T}-x_{s}\right)+k_{f} I=F \\
\left(m_{T}+b\right) \ddot{x}_{T}+k_{T}\left(x_{T}-x_{s}\right)-k_{f} I=0, \\
k_{v}\left(\dot{x}_{T}-\dot{x}_{s}\right)+R I+L \dot{I}+\frac{1}{C} \int I d t=0
\end{array}
$$

when the primary structure is undamped, the above can be simplified in the Laplace domain:

$$
\begin{array}{r}
m_{s} x_{s} s^{2}+k_{s} x_{s}-k_{T}\left(x_{T}-x_{s}\right)+k_{f} I=F, \\
\left(m_{T}+b\right) x_{T} s^{2}+k_{T}\left(x_{T}-x_{s}\right)-k_{f} I=0, \\
k_{v}\left(x_{T}-x_{s}\right) s+R I+L I s+\frac{I}{C s}=0 ;
\end{array}
$$

normalizing the frequency and setting $s=j \omega$, we can have

$$
\begin{aligned}
& x_{s}(j \alpha)^{2}+x_{s}-\mu f_{T}^{2}\left(x_{T}-x_{s}\right)+\frac{k_{f}}{k_{s}} I=\frac{F}{k_{s}}, \\
& (1+\delta) x_{T}(j \alpha)^{2}+f_{T}^{2}\left(x_{T}-x_{s}\right)-\frac{k_{f}}{\mu k_{s}} I=0, \\
& k_{v}\left(x_{T}-x_{s}\right)(j \alpha)+2 \zeta_{e} f_{e} L I+L I(j \alpha)+I L f_{e}^{2} \frac{1}{(j \alpha)} \\
& \quad=0
\end{aligned}
$$




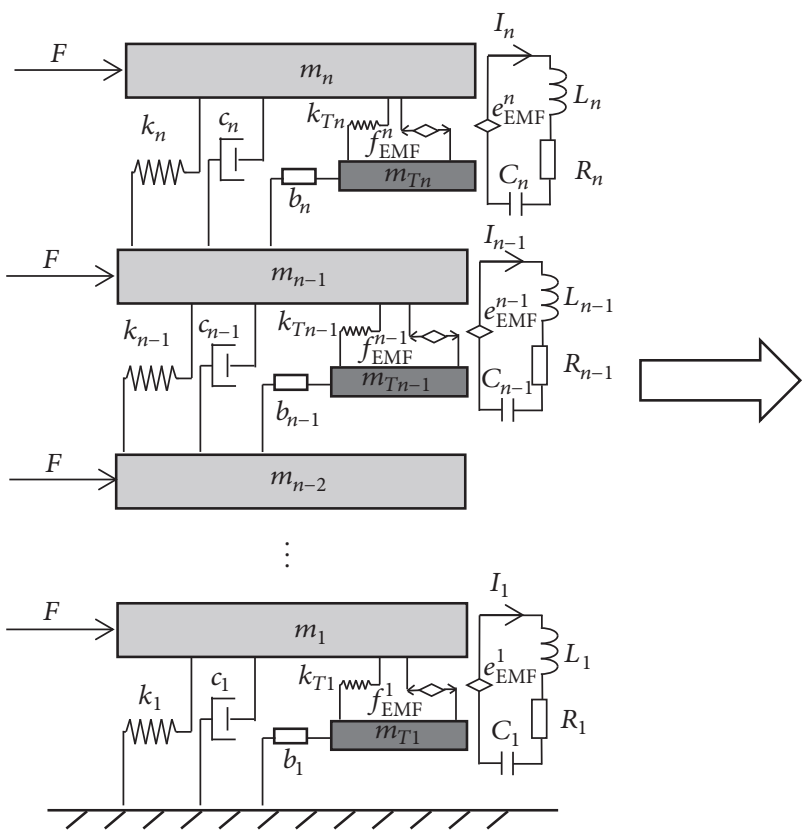

(a)

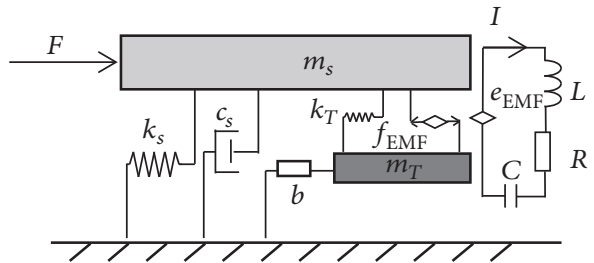

(b)

FIGURE 1: Schematic of the coupled structure and tuning damper system: (a) a general MDOF and (b) the SDOF structure-damper system.

rewriting relative displacement $x_{r}=x_{T}-x_{s}$,

$$
\begin{aligned}
& x_{s}\left((j \alpha)^{2}+1\right)-\mu f_{T}^{2} x_{r}+\frac{k_{f}}{k_{s}} I=\frac{F}{k_{s}}, \\
& x_{r}\left((1+\delta)(j \alpha)^{2}+f_{T}^{2}\right)+x_{s}(1+\delta)(j \alpha)^{2}-\frac{k_{f}}{\mu k_{s}} I=0, \\
& k_{v} x_{r}(j \alpha)+L I\left(2 \zeta_{e} f_{e}+(j \alpha)+f_{e}^{2} \frac{1}{(j \alpha)}\right)=0,
\end{aligned}
$$

where the nature frequency of the primary structure $\omega_{s}=$ $\sqrt{k_{s} / m_{s}}$, the nature frequency of the absorber $\omega_{T}=\sqrt{k_{T} / m_{T}}$, the resonant frequency of the circuit $\omega_{e}=1 / \sqrt{L C}$, the mass ratio of the absorber to the primary structure $\mu=m_{T} / m_{s}$, the mass ratio of inertance to the primary structure $\delta=$ $b / m_{T}$, the mechanical tuning ratio $f_{T}=\omega_{T} / \omega_{s}$, the electrical tuning ratio $f_{e}=\omega_{e} / \omega_{s}$, the normalized frequency $\alpha=$ $\omega / \omega_{s}$, and the electrical damping ratio of the circuit $\zeta_{e}=$ $R /\left(2 L \omega_{e}\right)$, where the total resistance $R=R_{i}+R_{e}$ and $R_{e}$ is the equivalent external load; the electromagnetic mechanical coupling coefficient $\mu_{k}=k_{v} k_{f} /\left(k_{T} L\right)$, where $k_{v}$ and $k_{f}$ are the voltage constant and the force constant of the electromagnetic transducer.

\section{3. $H_{2}$ Optimization for the ERS-TMDI}

3.1. Vibration Mitigation of the ERS-TMDI. If the system suffered from the wind force rather than the sinusoidal excitation, $\mathrm{H}_{2}$ optimization is more desirable for evaluating the system performance for it is the root mean square (RMS) value of the performance under unit Gaussian white noise input. This is a good approximation when the frequency of the wind force is broad when compared with the natural frequency of the building. For mitigating the vibration of the primary structure when subjected to the excitation force $F$, $\mathrm{H}_{2}$ norm is minimized from $\mathrm{F} / \mathrm{k}_{\mathrm{s}}$ to the deformation of the primary structure and $x_{s}$ is defined as

$$
\mathrm{PI}_{v}=\frac{E\left[x_{s}^{2}\right]}{2 \pi \omega_{s} S_{0}}=\frac{\left\langle x_{s}^{2}\right\rangle}{2 \pi \omega_{s} S_{0}}
$$

where the symbols $E[\cdot]$ and $\langle\cdot\rangle$ refer to the ensemble and temporal averages, respectively, and $S_{0}$ is the uniform power spectrum function. The RMS value of the deformation of the SDOF structure mass $x_{s}$ can be obtained as

$$
\left\langle x_{s}^{2}\right\rangle=\omega_{s} S_{0} \int_{-\infty}^{\infty}\left|X_{n}\right|^{2} d \alpha,
$$

where $X_{n}$ in (6) is the norm of the frequency response function from $F / k_{s}$ to the deformation of the primary structure $x_{s}$ and $j=\sqrt{-1}$ is the unit imaginary number. Substituting (6) into (5), the performance index $\mathrm{PI}_{v}$ in (5) can be expressed as

$$
\mathrm{PI}_{v}=\frac{1}{2 \pi} \int_{-\infty}^{\infty}\left|X_{n}\right|^{2} d \alpha
$$

In addition, the normalized frequency response function $X_{n}$ from $F / k_{s}$ to $x_{s}$ can be written in the dimensionless form by using the aforementioned dimensionless parameters, which is 
$X_{n}=\frac{x_{s}}{F / k_{s}}=\frac{f_{e}^{2} f_{T}^{2}+2 f_{e} f_{T}^{2} \zeta_{e}(j \alpha)+\left(f_{e}^{2} \psi+f_{T}^{2}\left(1+\mu_{k}\right)\right)(j \alpha)^{2}+2 f_{e} \psi \zeta_{e}(j \alpha)^{3}+\psi(j \alpha)^{4}}{A_{0}+A_{1}(j \alpha)+A_{2}(j \alpha)^{2}+A_{3}(j \alpha)^{3}+A_{4}(j \alpha)^{4}+A_{5}(j \alpha)^{5}+A_{6}(j \alpha)^{6}}$

$A_{0}=f_{e}^{2} f_{T}^{2}, A_{1}=2 f_{T}^{2} f_{e} \zeta_{e}, A_{2}=f_{e}^{2} \psi+f_{T}^{2}\left(1+\mu_{k}\right)+f_{e}^{2} f_{T}^{2}(1+\mu \psi), A_{3}=2 f_{e} \zeta_{e}\left(\psi+f_{T}^{2}(1+\mu \psi)\right), A_{4}=f_{T}^{2}\left(1+\mu_{k}\right)(1+\mu \psi)+\left(1+f_{e}^{2}\right) \psi, A_{5}=2 f_{e} \zeta_{e} \psi, A_{6}=\psi$,

where $\psi=1+\delta$.

The integral in (7) can be solved using the general formula in [40]. Hence, the performance index in (7) can be obtained as a function of the four design parameters $f_{T}, \mu_{k}, f_{e}, \zeta_{e}$ and the given parameters $\mu, \psi$.

$$
\begin{aligned}
\mathrm{PI}_{v} & =\frac{1}{4 f_{e} f_{T}^{2} \mu_{k} \zeta_{e} \mu \psi^{2}}\left(\psi^{2}+f_{e}^{4} \psi^{2}+f_{e}^{2} \psi^{2}\left(-2+4 \zeta_{e}^{2}\right)\right. \\
& +f_{T}^{2}\left(-2\left(1+\mu_{k}\right) \psi-2 f_{e}^{4} \psi(1+\mu \psi)+f_{e}^{2} \psi(2\right. \\
& \left.\left.+2\left(1+\mu_{k}\right)+\mu \psi+\mu\left(1+\mu_{k}\right) \psi-8 \zeta_{e}^{2}-4 \mu \psi \zeta_{e}^{2}\right)\right) \\
& +f_{T}^{4}\left(\left(1+\mu_{k}\right)^{2}+\mu\left(1+\mu_{k}\right)^{2} \psi+f_{e}^{4}(1+3 \mu \psi\right. \\
& \left.+3 \mu^{2} \psi^{2}+\mu^{3} \psi^{3}\right)+f_{e}^{2}\left(-2\left(1+\mu_{k}\right)-4 \mu\left(1+\mu_{k}\right) \psi\right. \\
& \left.\left.\left.-2 \mu^{2}\left(1+\mu_{k}\right) \psi^{2}+4 \zeta_{e}^{2}+8 \mu \psi \zeta_{e}^{2}+4 \mu^{2} \psi^{2} \zeta_{e}^{2}\right)\right)\right) .
\end{aligned}
$$

To minimize the performance index $\mathrm{PI}_{v}$ regarding the vibration mitigation performance, the derivatives of $\mathrm{PI}_{v}$ with respect to all the design parameters should be equal to zero. Thus, we have

$$
\begin{aligned}
& \frac{\partial \mathrm{PI}_{v}}{\partial f_{T}}=0, \\
& \frac{\partial \mathrm{PI}_{v}}{\partial \zeta_{e}}=0 \\
& \frac{\partial \mathrm{PI}_{v}}{\partial f_{e}}=0, \\
& \frac{\partial \mathrm{PI}}{\partial \mu_{k}}=0 .
\end{aligned}
$$

Therefore, the following simultaneous gradients' equations can be obtained from (10):

$$
\begin{gathered}
f_{T}^{4}\left(1+\mu_{k}\right)^{2}(1+\mu \psi)+f_{e}^{4} f_{T}^{4}(1+\mu \psi)^{3} \\
-2 f_{e}^{2} f_{T}^{4}(1+\mu \psi)^{2}\left(1+\mu_{k}-2 \zeta_{e}^{2}\right) \\
-\psi^{2}\left(1+f_{e}^{4}+f_{e}^{2}\left(-2+4 \zeta_{e}^{2}\right)\right)=0,
\end{gathered}
$$

$$
\begin{aligned}
& -2 f_{T}^{2}\left(1+\mu_{k}\right) \psi+\left(f_{T}^{4}\left(1+\mu_{k}\right)^{2}-2 f_{e}^{4} f_{T}^{2} \psi\right) \\
& \cdot(1+\mu \psi)+f_{e}^{4} f_{T}^{4}(1+\mu \psi)^{3}-2 f_{e}^{2} f_{T}^{4}(1+\mu \psi)^{2} \\
& \cdot\left(1+\mu_{k}+2 \zeta_{e}^{2}\right)+f_{e}^{2} f_{T}^{2} \psi(2+\mu \psi)\left(2+\mu_{k}+4 \zeta_{e}^{2}\right) \\
& +\psi^{2}\left(1+f_{e}^{4}-2 f_{e}^{2}\left(1+2 \zeta_{e}^{2}\right)\right)=0 \\
& 2 f_{T}^{2}\left(1+\mu_{k}\right) \psi+\left(-f_{T}^{4}\left(1+\mu_{k}\right)^{2}-6 f_{e}^{4} f_{T}^{2} \psi\right) \\
& \cdot(1+\mu \psi)+3 f_{e}^{4} f_{T}^{4}(1+\mu \psi)^{3}+f_{e}^{2} f_{T}^{2} \psi(2+\mu \psi) \\
& \cdot\left(2+\mu_{k}-4 \zeta_{e}^{2}\right)-2 f_{e}^{2} f_{T}^{4}(1+\mu \psi)^{2} \\
& \cdot\left(1+\mu_{k}-2 \zeta_{e}^{2}\right) \\
& +\psi^{2}\left(-1+3 f_{e}^{4}+f_{e}^{2}\left(-2+4 \zeta_{e}^{2}\right)\right)=0, \\
& -2 f_{T}^{2} \psi+\left(f_{T}^{4}\left(1-\mu_{k}^{2}\right)-2 f_{e}^{4} f_{T}^{2} \psi\right)(1+\mu \psi) \\
& +f_{e}^{4} f_{T}^{4}(1+\mu \psi)^{3}+2 f_{e}^{2} f_{T}^{4}(1+\mu \psi)^{2}\left(-1+2 \zeta_{e}^{2}\right) \\
& -2 f_{e}^{2} f_{T}^{2} \psi(2+\mu \psi)\left(-1+2 \zeta_{e}^{2}\right) \\
& +\psi^{2}\left(1+f_{e}^{4}+f_{e}^{2}\left(-2+4 \zeta_{e}^{2}\right)\right)=0
\end{aligned}
$$

Solving this set of equations is nontrivial as it involves multiple nonlinear, high-order variables, but in the following we will simply summarize the solving process and then directly present the final results. This will highlight the results and avoid prolixity. By combining (11d) with the other three equations in (11a), (11b), (11c), and (11d) we can eliminate $\zeta_{e}$ to obtain a new equation set in design variables $f_{T}, \mu_{k}, f_{e}$. Then using similar manipulations, we can also eliminate $f_{T}$ and $f_{e}$ from the new equation set and obtain (11a), (11b), (11c), and (11d) in only variable $\mu_{k}$. Similarly, $H_{2}$ norms optimal can be obtained by (11a), (11b), (11c), and (11d) as

$$
\begin{aligned}
& f_{T}^{\mathrm{opt}}=\frac{\sqrt{\psi(r-\mu \psi)}}{2(1+\mu \psi)} \\
& \mu_{k}^{\mathrm{opt}}=\frac{4 \mu \psi(4+6 \mu \psi+r)}{16+19 \mu \psi},
\end{aligned}
$$




$$
\begin{aligned}
& f_{e}^{\mathrm{opt}}=\sqrt{\frac{32+25 \mu^{2} \psi^{2}+\mu \psi(58+r)}{2\left(16+35 \mu \psi+19 \mu^{2} \psi^{2}\right)}}, \\
& \zeta_{e}^{\mathrm{opt}}=\frac{\sqrt{\left(1 /(16+19 \mu \psi) \mu \psi\left(70 \mu^{3} \psi^{3}+24(4+r)+4 \mu \psi(68+11 r)+\mu^{2} \psi^{2}(247+18 r)\right)\right)}}{\sqrt{16+23 \mu \psi+8 \mu^{2} \psi^{2}}},
\end{aligned}
$$

where $r=\sqrt{16+32 \mu \psi+17 \mu^{2} \psi^{2}}$.

At $\mathrm{H}_{2}$ optimal tuning condition, the performance index $\mathrm{PI}_{v}^{\mathrm{opt}}$ is

$\mathrm{PI}_{v}^{\mathrm{opt}}$
$=\frac{-\left(\sqrt{8+23 \mu \psi / 2+4 \mu^{2} \psi^{2}}\left(784 \mu^{4} \psi^{4}+192(4+r)+20 \mu \psi(156+31 r)+\mu^{3} \psi^{3}(3147+232 r)+\mu^{2} \psi^{2}(4716+661 r)\right)\right)}{\left(2(1+\mu \psi)(16+19 \mu \psi)(\mu \psi-r)(4+6 \mu \psi+r) \sqrt{\left(32+25 \mu^{2} \psi^{2}+\mu \psi(58+r)\right) /\left(16+35 \mu \psi+19 \mu^{2} \psi^{2}\right)} \sqrt{\mu \psi\left(70 \mu^{3} \psi^{3}+24(4+r)+4 \mu \psi(68+11 r)+\mu^{2} \psi^{2}(247+18 r)\right) /(16+19 \mu \psi)}\right)}$

Because the mass ratio $\mu$ is a pretty small number, regularly less than 0.1 for building-TMD systems, the square root term $r=\sqrt{16+32 \mu \psi+17 \mu^{2} \psi^{2}}$ can be about as $4(1+\mu \psi)$ by segmentally ignoring the terms involving second powers in $\mu \psi$. Hence, a compendious, approximate solution set can be obtained as

$$
\begin{aligned}
& f_{T}^{\text {opt* }}=\frac{\sqrt{\psi(4+3 \mu \psi)}}{2(1+\mu \psi)}, \\
& \mu_{k}^{\text {opt* }}=\frac{4 \mu \psi(8+10 \mu \psi)}{16+19 \mu \psi},
\end{aligned}
$$$$
\begin{aligned}
& f_{e}^{\mathrm{opt} *}=\sqrt{\frac{32+29 \mu^{2} \psi^{2}+62 \mu \psi}{2\left(16+35 \mu \psi+19 \mu^{2} \psi^{2}\right)}}, \\
& \zeta_{e}^{\text {opt* }} \\
& =\frac{\sqrt{\left(1 /(16+19 \mu \psi) \mu \psi\left(142 \mu^{3} \psi^{3}+495 \mu^{2} \psi^{2}+544 \mu \psi+192\right)\right)}}{\sqrt{16+23 \mu \psi+8 \mu^{2} \psi^{2}}}
\end{aligned}
$$

with the approximate optimal performance index $\mathrm{PI}_{v}^{\mathrm{opt} *}$,
Therefore, it is easy to obtain the corresponding optimal absorber stiffness $k_{T}^{\mathrm{opt}}$, the inductance $L^{\mathrm{opt}}$, the capacitance $C^{\mathrm{opt}}$, and the total resistance $R^{\mathrm{opt}}$ with the above parameters,

$$
\begin{aligned}
L^{\mathrm{opt}} & =\frac{k_{v} k_{f}}{\mu_{k}^{\mathrm{opt}} f_{T}^{\mathrm{opt}^{2}} m_{T} \omega_{s}^{2}}, \\
k_{T}^{\mathrm{opt}} & =f_{T}^{\mathrm{opt}^{2}} m_{T} \omega_{s}^{2}, \\
R^{\mathrm{opt}} & =\frac{2 k_{v} k_{f} \zeta_{e}^{\mathrm{opt}} f_{e}^{\mathrm{opt}}}{\mu_{k}^{\mathrm{opt}} f_{T}^{\mathrm{opt}^{2}} m_{T} \omega_{s}}, \\
C^{\mathrm{opt}} & =\frac{m_{T} \mu_{k}^{\mathrm{opt}^{\mathrm{opt}}} f_{T}^{\mathrm{opt}^{2}}}{k_{v} k_{f} f_{e}^{\mathrm{opt}^{2}}} .
\end{aligned}
$$

Moreover, there is the need to declare that $H_{2}$ tuning law for the classical TMD system is [41]

$$
\begin{aligned}
f^{\mathrm{opt}} & =\frac{1}{1+\mu} \sqrt{\frac{2+\mu}{2}}, \\
\zeta^{\mathrm{opt}} & =\sqrt{\frac{\mu(4+3 \mu)}{8(1+\mu)(2+\mu)}} .
\end{aligned}
$$

Moreover, the approximate $\mathrm{H}_{2}$ tuning law for the ERS-TMDs is [42]

$$
\begin{aligned}
& f_{T}^{\mathrm{opt} * *}=\frac{\sqrt{4+3 \mu}}{2(1+\mu)}, \\
& \mu_{k}^{\mathrm{opt} * *}=\frac{32 \mu+40 \mu^{2}}{16+19 \mu},
\end{aligned}
$$




$$
\begin{aligned}
& f_{e}^{\mathrm{opt} * *}=\sqrt{\frac{32+62 \mu+29 \mu^{2}}{2\left(16+35 \mu+19 \mu^{2}\right)}}, \\
& \zeta_{e}^{\mathrm{opt} * *}=\sqrt{\frac{\mu(192+544 \mu+495)}{256-96 \mu-27 \mu^{2}}} .
\end{aligned}
$$

$$
\begin{aligned}
& \zeta_{2 \mathrm{opt}}=0 \\
& \zeta_{3 \mathrm{opt}}=\frac{1}{2} \sqrt{\frac{3 \mu}{1+2 \mu}}
\end{aligned}
$$

And the optimal parameters of the series-type double-mass TMDs [37] are

$$
\begin{aligned}
\mu_{\text {Bopt }} & =2 \mu, \\
v_{\text {opt }} & =\sqrt{1+2 \mu}, \\
v_{\text {Bopt }} & =\frac{1}{1+2 \mu},
\end{aligned}
$$

$$
X_{r}=\frac{x_{r}}{F / k_{s}}=-\frac{f_{e}^{2} \psi(j \alpha)^{2}+2 \psi f_{e} \zeta_{e}(j \alpha)^{3}+\psi(j \alpha)^{4}}{A_{0}+A_{1}(j \alpha)+A_{2}(j \alpha)^{2}+A_{3}(j \alpha)^{3}+A_{4}(j \alpha)^{4}+A_{5}(j \alpha)^{5}+A_{6}(j \alpha)^{6}} .
$$

\subsection{Energy Harvesting of the Electromagnetic Resonant Shunt} Tuned Mass-Damper-Inerter. To optimize the energy harvesting of the ERS-TMDI, it is our wish to maximize the average electrical power on the external load $R_{e}$. The instant power on the external load is

$$
P=R_{e} I^{2}
$$

where $\mu_{B \text { opt }}$ is the mass ratio of the further mass to the closer mass; $\nu_{\text {opt }}$ is the undamped natural frequency ratio of the closer mass to the primary system; $\nu_{\text {Bopt }}$ is the undamped natural frequency ratio of the further mass to the closer mass; $\zeta_{2 \text { opt }}$ is the damping ratio of the closer mass; $\zeta_{3 \mathrm{opt}}$ is the damping ratio of the closer mass.

In addition, the normalized frequency response function $X_{r}$ from $F / k_{s}$ to the relative displacement of the primary structure $x_{r}$ can also be expressed in the dimensionless form by using the aforementioned dimensionless parameters, which are

$$
I_{n}=\frac{I}{F / k_{s}}=\frac{\left(k_{v} / L\right) \psi(j \alpha)^{4}}{A_{0}+A_{1}(j \alpha)+A_{2}(j \alpha)^{2}+A_{3}(j \alpha)^{3}+A_{4}(j \alpha)^{4}+A_{5}(j \alpha)^{5}+A_{6}(j \alpha)^{6}} ;
$$

similarly, the normalized frequency response function from $F / k_{s}$ to $\sqrt{P}$ can also be written:

$$
P_{n}=\frac{\sqrt{P}}{F / k_{s}}=\frac{I_{n} \sqrt{R_{e}}}{\ddot{x}_{g} / \omega_{s}^{2}} \text {. }
$$

At the optimal $\mathrm{H}_{2}$ tuning condition, the performance index $\mathrm{PI}_{e}$ is

$$
\mathrm{PI}_{e}=\frac{k_{v}^{2}}{4 f_{e} f_{T}^{2} \mu_{k} \zeta_{e} \mu(1+\delta) L^{2}}
$$

\section{Numerical Analyses}

\subsection{Frequency-Domain Analyses of the ERS-TMDI}

4.1.1. Comparing of $\mathrm{H}_{2}$ Tuning Laws of Exact and Approximate Solutions. Figure 2 graphically depicts $\mathrm{H}_{2}$ tuning laws for the vibration mitigation when the primary structure is subjected
The normalized frequency response function from $F / k_{s}$ to $I$ can be written in the dimensionless form by using the aforementioned dimensionless parameters, which are to the force acceleration. It is obvious to see that the error between the exact solution and the approximate solution for the force excitation system is extremely small. Therefore, the approximate solution is a good alternative to avoid computational complexities in practice.

4.1.2. Three-Dimensional Graphical Representations of $\mathrm{H}_{2}$ Tuning Laws for Approximate Solutions. Figure 3 graphically depicts $\mathrm{H}_{2}$ tuning laws of approximate solutions in a threedimensional way for the vibration mitigation when the primary structure is subjected to the force excitations.

4.1.3. Comparing Performances of Different Systems. $H_{2}$ performances of vibration mitigation of the deformation of the primary structure and the relative deformation of five types of SDOF systems are compared under the same mass ratio of 0.02. From Figure 4, it is clear that the ERS-TMDI is superior to mitigate the vibration of the primary structure nearly across the whole frequency spectrum for force excitation 


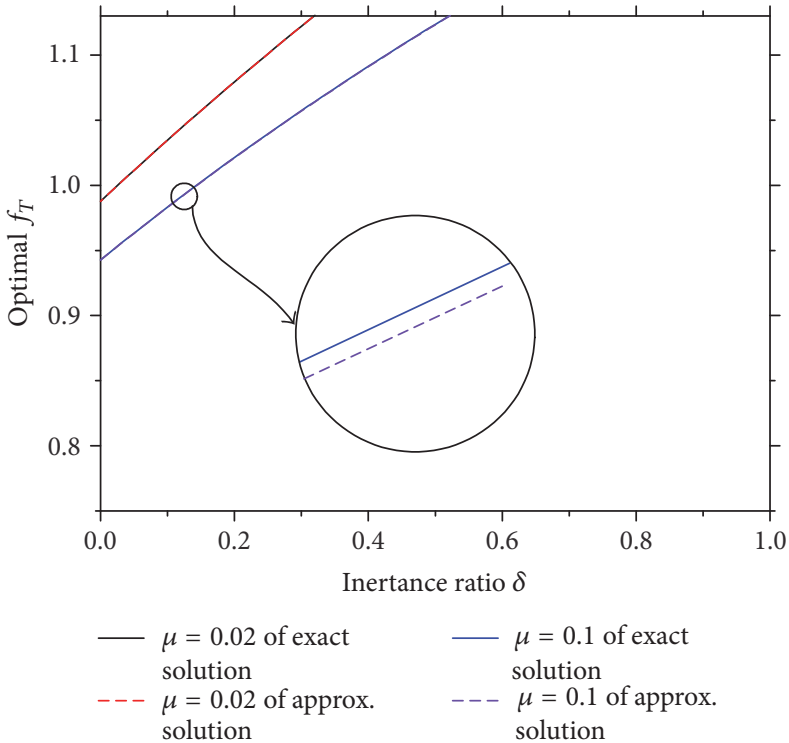

(a)

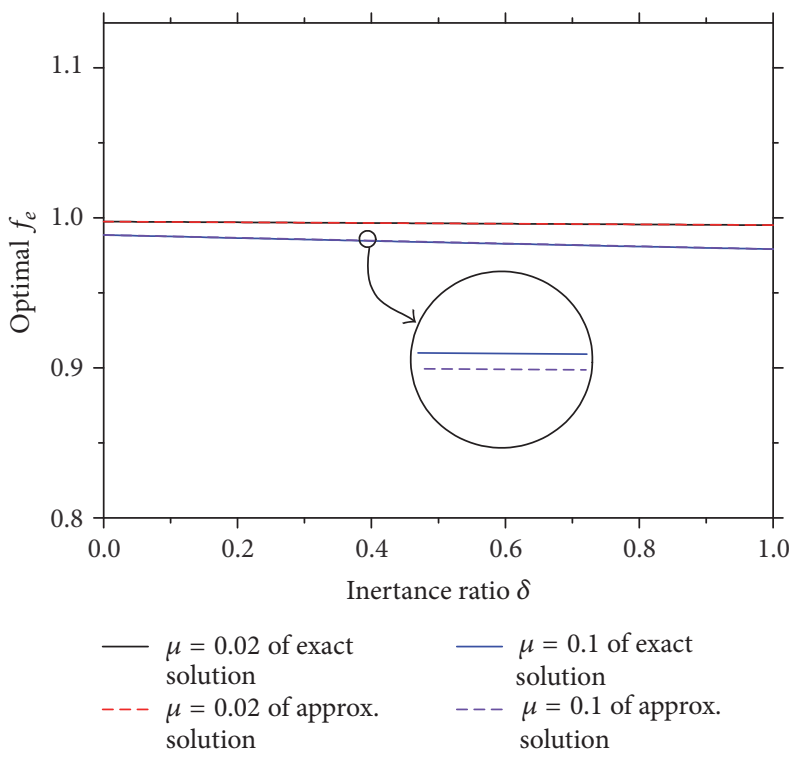

(c)

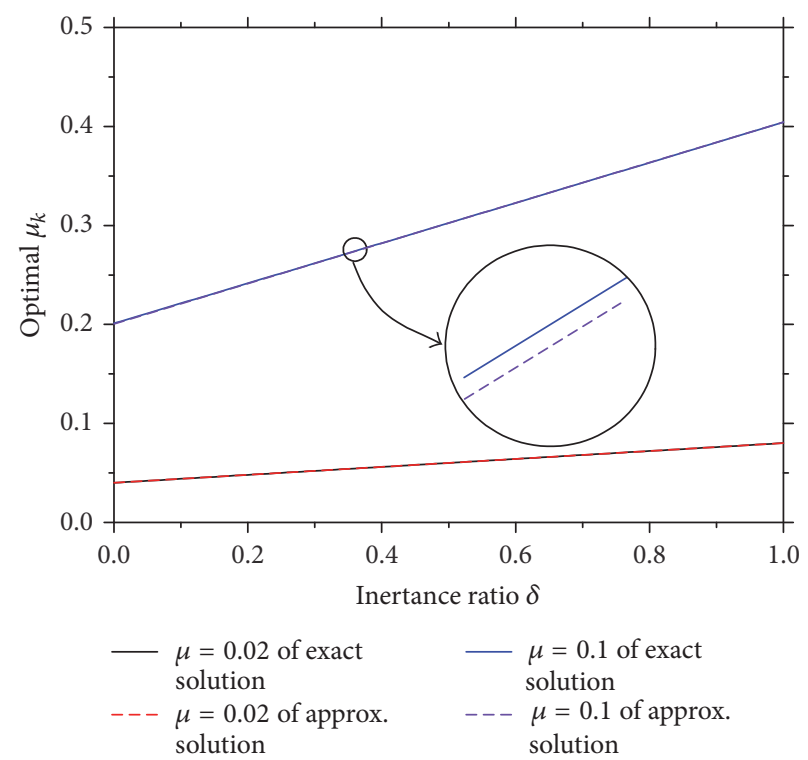

(b)

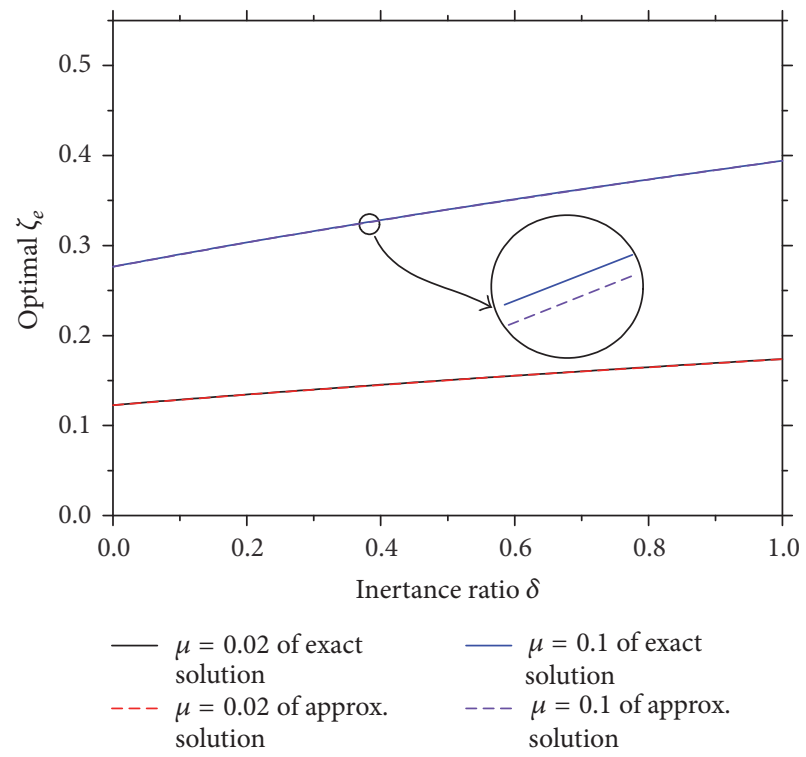

(d)

Figure 2: Graphical representations of $H_{2}$ tuning laws. (a) Optimal mechanical tuning ratio $f_{T}$; (b) optimal electromagnetic mechanical coupling coefficient $\mu_{k} ;$ (c) optimal electrical tuning ratio $f_{e} ;$ (d) optimal electrical damping ratio $\zeta_{e}$ of exact and approximate solutions under different mass ratios.

system, as compared to that of classical TMD, ERS-TMDs, and system without a TMD, and the effective frequency band is also further widened. At their own resonant frequencies, the peak value of the normalized displacement $X_{n}$ in the ERS-TMDI system is reduced by around 35\% compared to that of the classical TMD, $18 \%$ to that of the ERS-TMDs, and $17 \%$ to that of series-type double-mass TMDs, while in the normalized displacement $X_{r}$, the relative reduction ratio to classical TMD and ERS-TMDs is $36 \%$ and $33 \%$.

4.1.4. Comparing Performances of the ERS-TMDI under Different Inertance Ratios. $\mathrm{H}_{2}$ performances of vibration mitigation of the deformation of the primary structure and the relative deformation of the ERS-TMDI are compared under different inertance ratios. From Figure $5, H_{2}$ norm of the ERSTMDI is better at the highest inertance ratio.

4.2. Time-Domain Analyses of the ERS-TMDI. In this section, the Taipei 101 tower will be taken as a case study to be computed for simulated wind in order to demonstrate the dual effect of the ERS-TMDI. Results are presented in comparison with the classical TMD.

4.2.1. Parameters of Simulation. In this section we take the Taipei 101 tower as a case study and illustrate the dual 


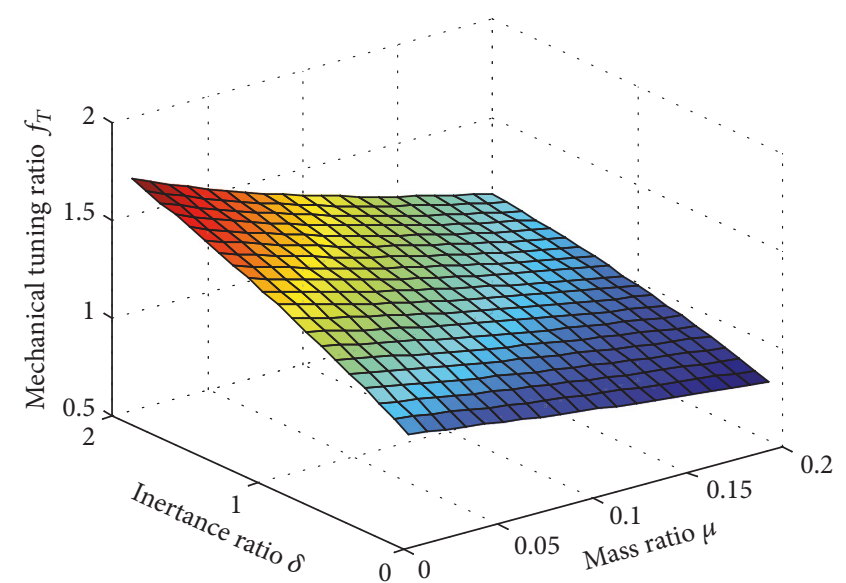

(a)

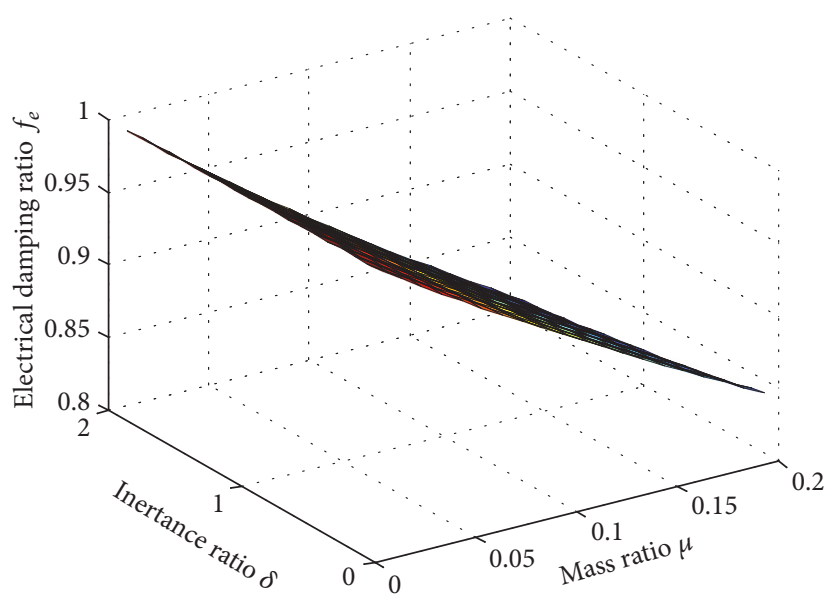

(c)

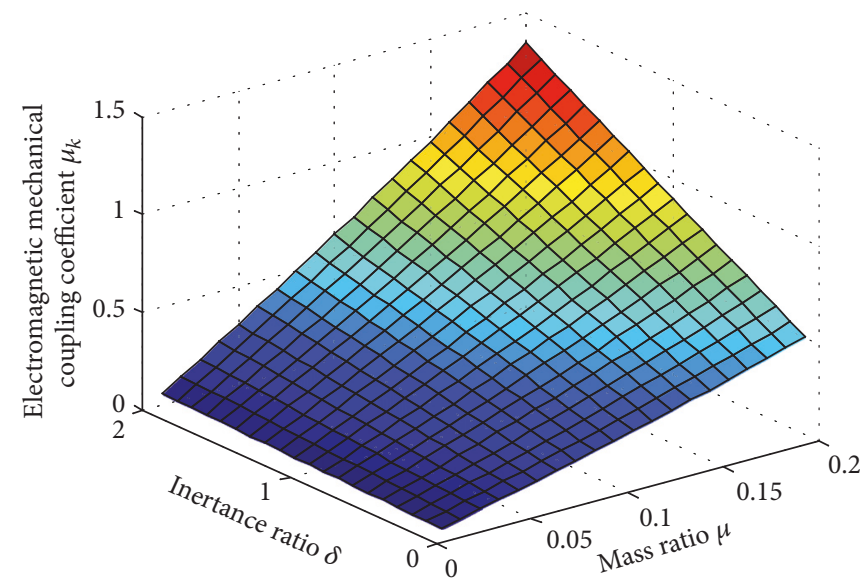

(b)

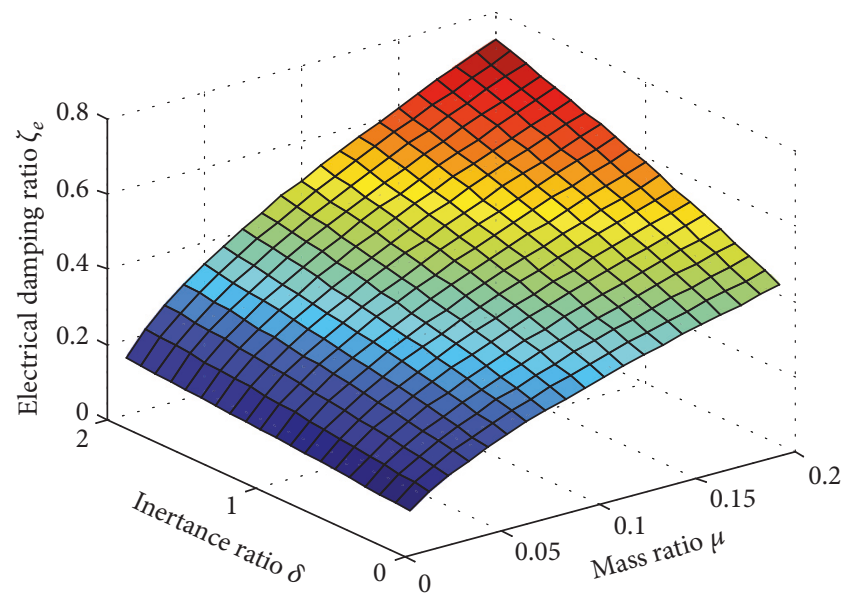

(d)

FIgURE 3: Three-dimensional graphical representations of $\mathrm{H}_{2}$ tuning laws. (a) Optimal mechanical tuning ratio $f_{T}$, (b) optimal electromagnetic mechanical coupling coefficient $\mu_{k}$, (c) optimal electrical tuning ratio $f_{e}$, and (d) optimal electrical damping ratio $\zeta_{e}$ of approximate solutions.

functions of ERS-TMDI. Results are presented in comparison with the classical TMD.

Taipei 101 is one of the tallest buildings in the world (449.2 $\mathrm{m}$ to roof and $509.2 \mathrm{~m}$ to spire). A TMD of 660 tonnes is suspended on the top of the building from the 92nd to the 87th floor to suppress the wind induced vibration [43]. The TMD is $0.78 \%$ of the modal mass, the first natural frequency is $0.146 \mathrm{~Hz}$, and inherent damping of the building is $1 \%$. In the case study, the parameters of the classical TMD are designed using $\mathrm{H}_{2}$ optimization as shown Table 1.

4.2.2. Wind Simulation. When the wind effect is analyzed, the Davenport wind spectrum expressed by (25a), (25b), and (25c) is taken as the target wind spectrum of wind velocity field [44]. The inverse fast Fourier transform method is used to generate the random fluctuating wind time series [45].

$$
S(\omega)=8 \pi \frac{n^{2} u_{*}^{2}}{\omega\left(1+n^{2}\right)^{4 / 3}},
$$

TABLE 1: The parameters of simulation.

\begin{tabular}{lcc}
\hline Description & Symbol & Value \\
\hline Primary structure mass & $m_{s}$ & $8.46 \times 10^{7}[\mathrm{~kg}]$ \\
Mechanical TMD mass & $m_{T}$ & $6.60 \times 10^{5}[\mathrm{~kg}]$ \\
Inertance mass & $b$ & $3.30 \times 10^{5}[\mathrm{~kg}]$ \\
Stiffness of the primary structure & $k_{s}$ & $7.12 \times 10^{7}[\mathrm{~N} / \mathrm{m}]$ \\
Stiffness of the mechanical TMD & $k_{T}$ & $8.21 \times 10^{5}[\mathrm{~N} / \mathrm{m}]$ \\
$\begin{array}{l}\text { Total inductance of electrical } \\
\text { resonator }\end{array}$ & $L$ & $1.17[\mathrm{H}]$ \\
$\begin{array}{l}\text { Total capacitance of electrical } \\
\text { resonator }\end{array}$ & $C$ & $1.02[\mathrm{~F}]$ \\
$\begin{array}{l}\text { Internal resistance of linear motor } \\
\text { External resistance }\end{array}$ & $R_{i}$ & $0.1[\Omega]$ \\
$\begin{array}{l}\text { The constant of the } \\
\text { electromagnetic transducer }\end{array}$ & $R_{e}$ & $0.1[\Omega]$ \\
\hline
\end{tabular}




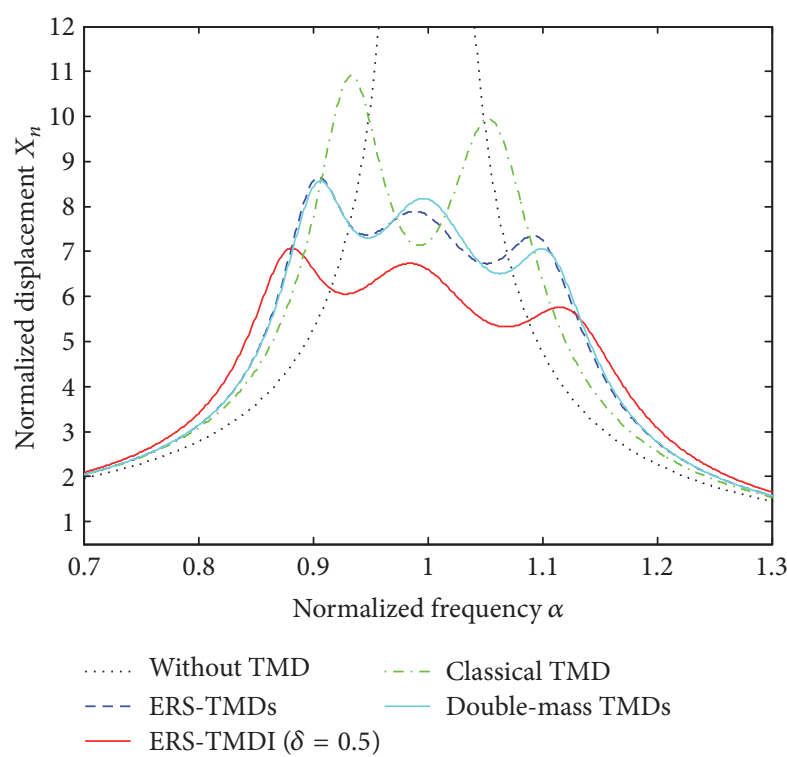

(a)

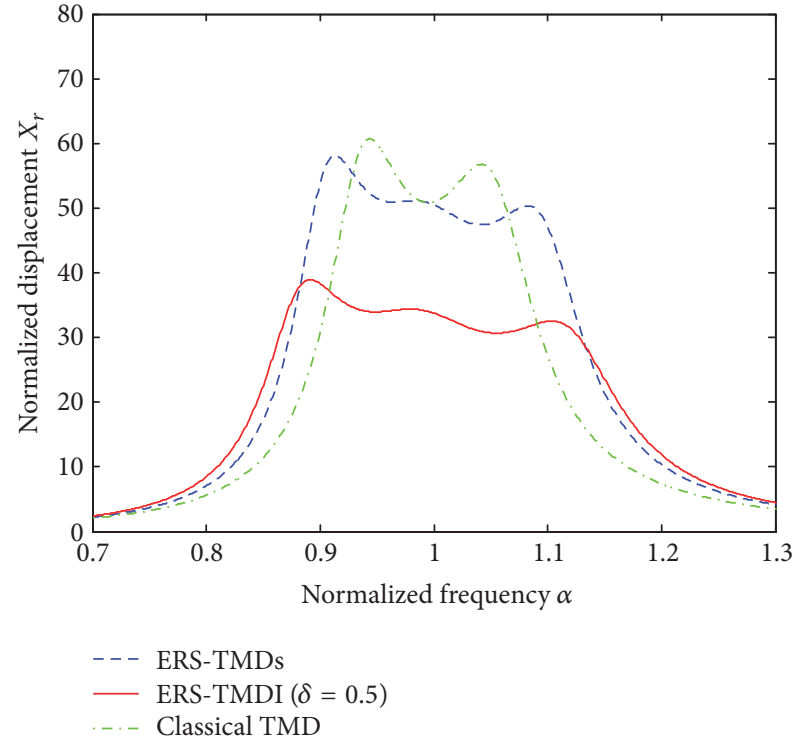

(b)

FIGURE 4: Schematic of the optimal frequency responses for types of SDOF system, where the mass ratio $\mu=0.02$. (a) The frequency response of the deformation of the primary structure and (b) the relative deformation of different buildings.

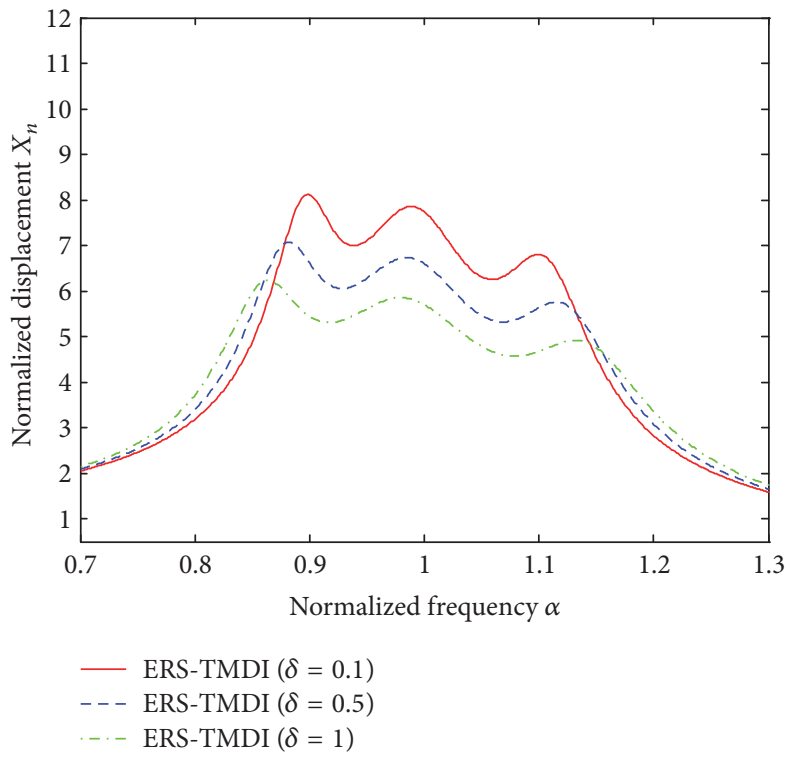

(a)

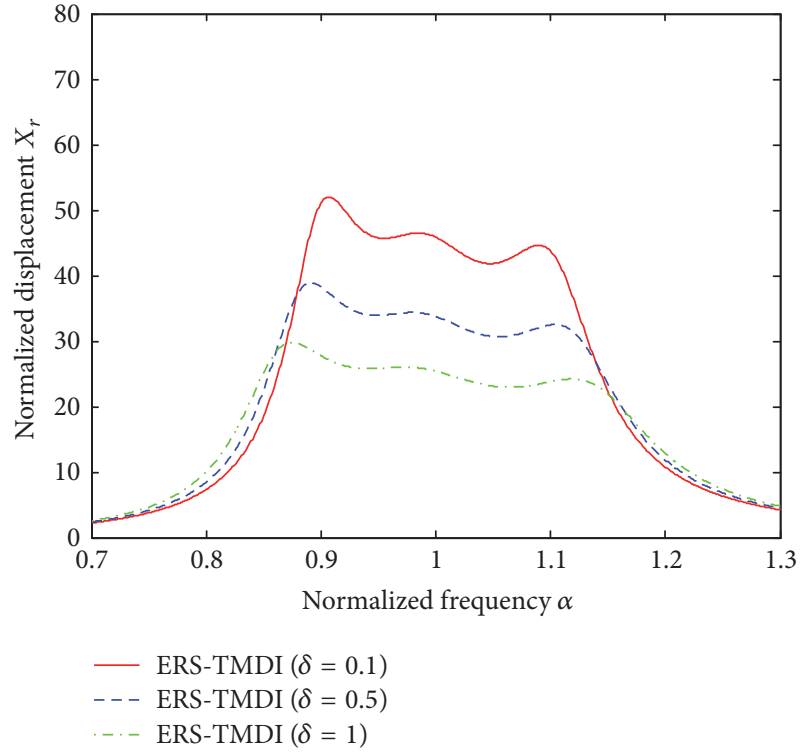

(b)

FIGURE 5: Schematic of the optimal frequency responses under different inertance ratio: (a) the deformation of the primary structure and (b) the relative deformation of the ERS-TMDI.

$$
\begin{gathered}
n=\frac{600 \omega}{\pi V_{10}}, \\
u_{*}=\frac{V_{z} K}{\ln \left(z / z_{0}\right)},
\end{gathered}
$$

where $S(\omega)$ is the power spectrum of velocity fluctuation; $\omega$ is the frequency of the fluctuating wind; $K$ is the terrain roughness factor of this area, which is $0.03 ; V_{10}$ is the mean wind speed, in $\mathrm{m} / \mathrm{s}$, at $10 \mathrm{~m}$. It is taken as $39.93 \mathrm{~m} / \mathrm{s}$, which means that 50 -year return period brings averaged over 10 minutes at a height of $10 \mathrm{~m} \mathrm{[46].} u_{*}$ is the shear velocity of the flow, $K=0.4$. $z$ is the height above the surface, $z_{0}$ is the roughness length, and $V_{z}$ is the mean wind speed of the height $z$.

Figure 6(a) is the typical fluctuating wind time history generated, whose duration is $1000 \mathrm{~s}$ and the time interval is $0.1 \mathrm{~s}$. As shown in Figure 6(b), the generated wind time history is converted to power spectral density by IFFT, which 


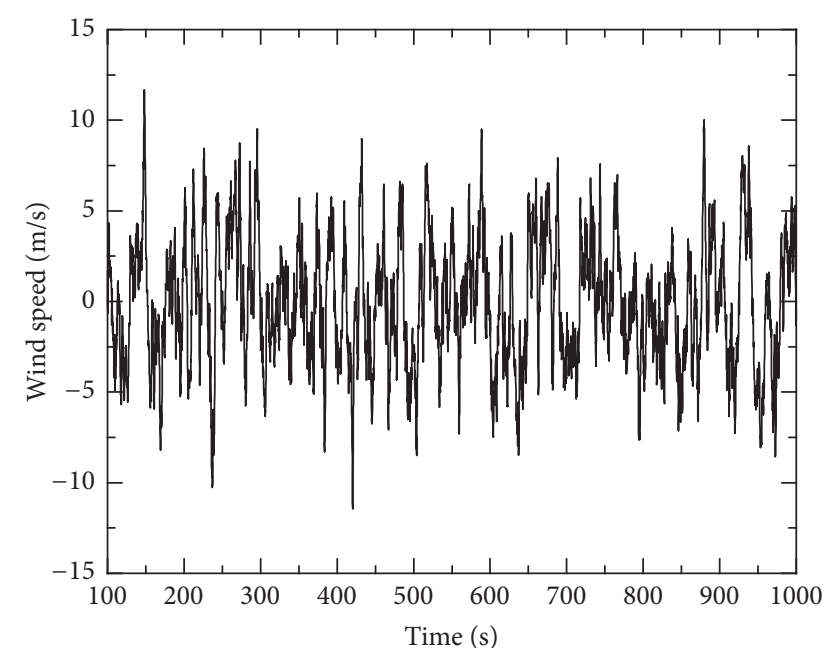

—— Wind speed

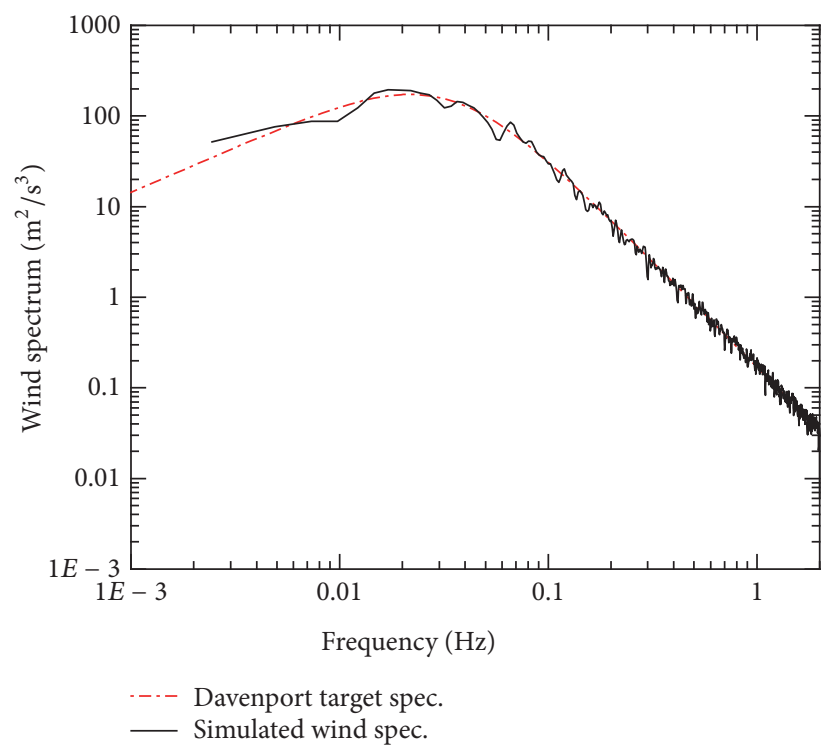

(b)

FIGURE 6: Simulated fluctuating wind time history: (a) wind speed and (b) power spectrum.

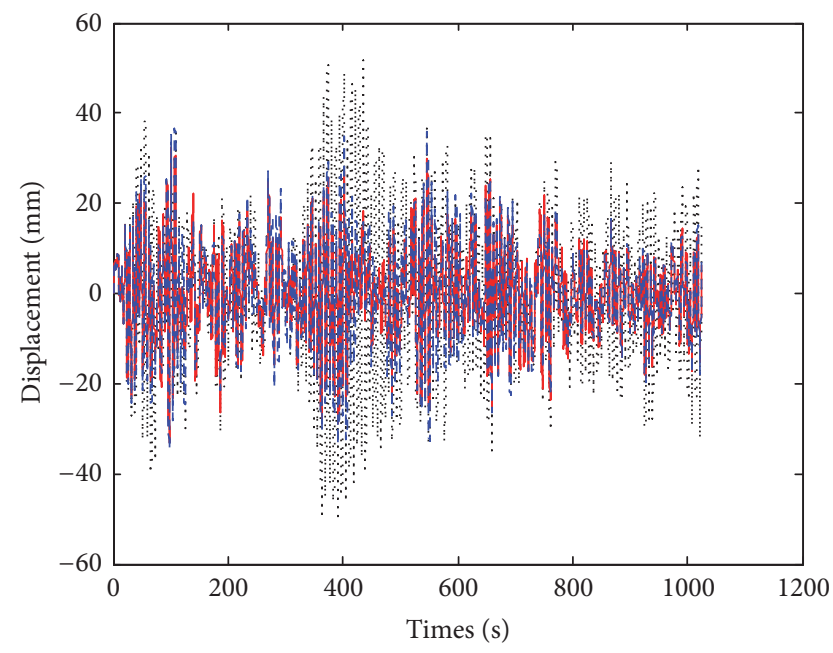

W.... Without control
ERS-TMDI
- - Classical TMD

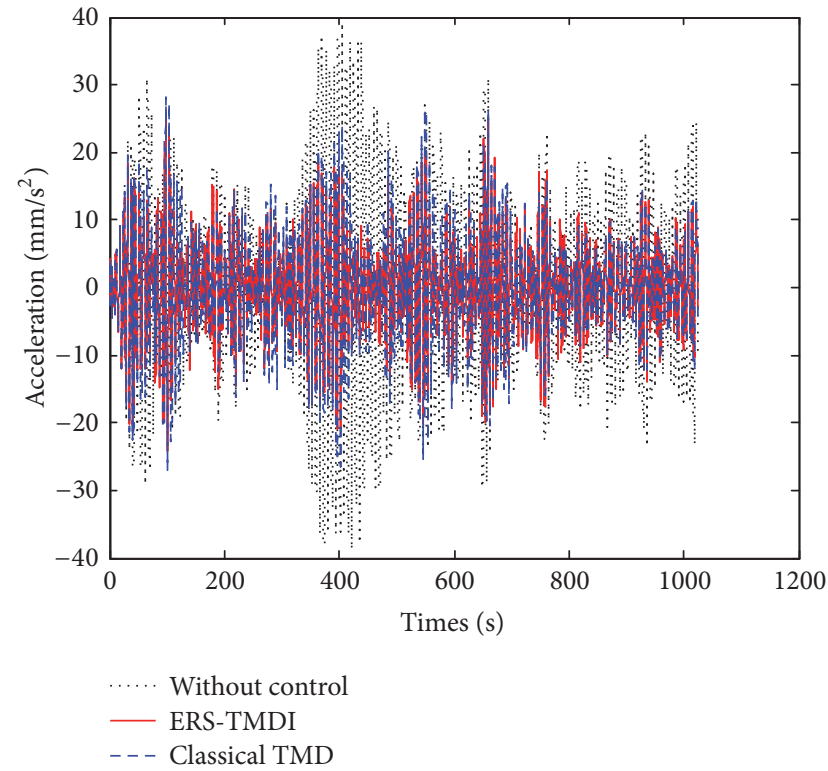

(b)

FIGURE 7: Time-history responses of (a) displacements and (b) accelerations of the primary structure: comparison between classical TMD and ERS-TMDI.

is compared with the target Davenport spectrum. It is shown that the simulated spectrum is in agreement with Davenport spectrum well in most frequency bands.

With the information above, one can calculate fluctuating wind force by the following expression:

$$
F(t)=\rho \cdot C_{D} \cdot A \cdot V_{10} \cdot u(t),
$$

where $\rho=1.28 \mathrm{~kg} / \mathrm{m}^{3}$ is the air density, $C_{D}=1.2$ is the drag coefficient, the tributary area assuming is $A=1600 \mathrm{~m}^{2}$, and $u(t)$ is the fluctuating wind speed.
4.2.3. The Performance of Vibration Mitigation. In the timehistory analyses, the characteristics of the model are identical to those used in the frequency-domain analyses described in Section 4.1.

From Figure 7, it is clear that the ERS-TMDI sufficiently reduces the displacement of the primary structure. In addition, the performance of the vibration mitigation of the ERSTMDI is clearly superior to that of the classical TMD. The peak value of the displacement of the primary structure specially is reduced by around $9.78 \%$ compared to that of the 
TABLE 2: The energy-related indicator.

\begin{tabular}{lcc}
\hline Peak power/w & Average power/w & Energy harvested $/ \mathrm{J}$ \\
\hline $1.34 \times 10^{3}$ & 132.32 & $1.39 \times 10^{5}$
\end{tabular}

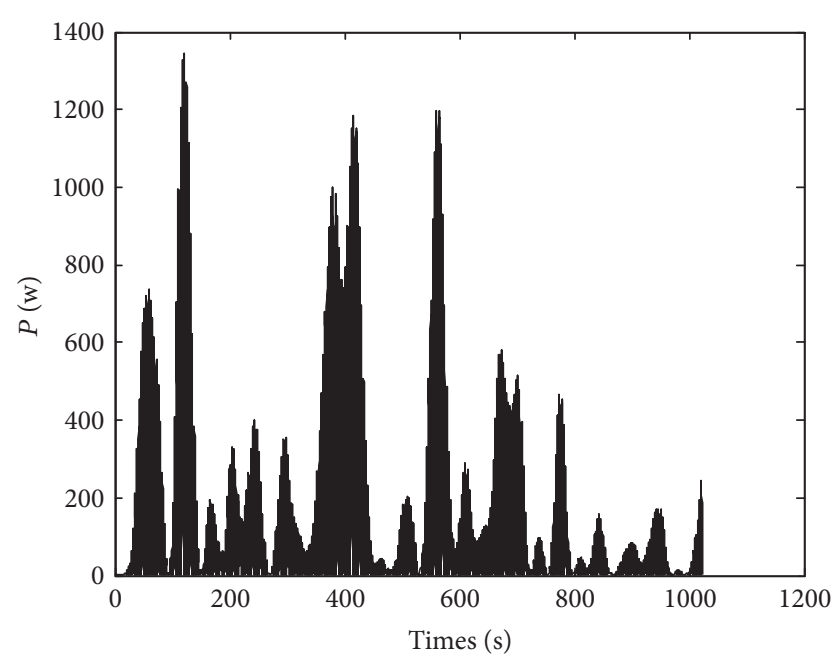

FIGURE 8: Time histories of the harvested power of ERS-TMDI.

classical TMD, while, in accelerations, the relative reduction ratio is $6.95 \%$. On the other hand, in the root mean square value of the primary structure displacement, the relative reduction is $9.71 \%$ and $11.49 \%$.

4.2.4. The Performance of Energy Harvesting. From Figure 8 and Table 2, it is clear that the ERS-TMDI can also adequately harvest the power, whose peak power, average power, and total energy harvested are $1.34 \times 10^{3} \mathrm{w}, 132.32 \mathrm{w}$, and $1.39 \times$ $10^{5} \mathrm{~J}$, respectively.

\section{Conclusions}

This paper investigates electromagnetic resonant shunt tuned mass-damper-inerter (ERS-TMDI) system, which consists of an auxiliary mechanical mass, an inertance mass, a spring, and an electromagnetic transducer shunted with an electrical RLC resonator. $\mathrm{H}_{2}$ tuning laws for the ERS-TMDI system are derived when the primary structure is subjected to wind excitations. Later on, the numerical analyses are conducted to illustrate the performance of vibration mitigation and energy harvesting.

From the frequency-domain analyses, it is shown that the ERS-TMDI can enhance performance in terms of both vibration control and energy harvesting due to tuning the resonances of the mechanical shock absorber, the inertance, and the electrical resonator, as compared to classical TMD, in which only the mechanical shock absorber is tuned. Particularly, the ERS-TMDI improves the vibration mitigation by reducing the resonant peak by $35 \%$ compared to that of the classical TMD, $18 \%$ compared to that of the ERS-TMDs, and $17 \%$ compared to that of the series-type double-mass TMDs, while, in the relative displacement, the reduction ratio to the classical TMD and ERS-TMDs is 36\% and 33\%. In addition, $\mathrm{H}_{2}$ performances of vibration mitigation of the deformation of the primary structure and the relative deformation of the ERS-TMDI are better at the higher inertance ratio.

From the time-domain analyses, it is shown that the ERSTMDI effectively reduces the peak and root mean square of the displacement, which is superior to the classical TMD. In addition, the ERS-TMDI can also harvest the power efficiently, with a peak power of $1.34 \times 10^{3} \mathrm{w}$, an average power of $132.32 \mathrm{w}$, and a total power of $1.39 \times 10^{5} \mathrm{~J}$.

\section{Conflicts of Interest}

The authors declare that they have no conflicts of interest.

\section{Acknowledgments}

This work was supported by National Natural Science Foundation of China under Grant 51508185, National Key Basic Research Scheme of China (973 program) under Grant 2015CB057702, and Natural Science Foundation of Hunan Province of China under Grant 2015JJ3073. The author Hongxin Sun is also grateful for the financial support from China Scholarship Council to conduct research as a visiting scholar in Lei Zuo's Lab at Virginia Tech.

\section{References}

[1] J. P. D. Hartog, Mechanical vibration, 1956.

[2] R. J. Mcnamara, “Tuned mass dampers for buildings," Journal of the Structural Division, vol. 1, pp. 1785-1798, 1977.

[3] J. C. H. Chang and T. T. Soong, "Structural control using active tuned mass damper," Journal of the Engineering Mechanics Division, vol. 106, no. 306, pp. 306-311, 1980.

[4] A. M. Kaynia, D. Veneziano, and J. M. Biggs, "Seismic effectiveness of tuned mass dampers," Journal of the Structural Division, vol. 107, pp. 1465-1484, 1981.

[5] J. S. Bae, J. H. Hwang, D. G. Kwag, J. Park, and D. J. Inman, "Vibration suppression of a large beam structure using tuned mass damper and eddy current damping," Shock \& Vibration, 10 pages, 2014.

[6] H. Frahm, Device for Damping Vibrations of Bodies, Google Patents, 1911.

[7] P. Irwin, J. Kilpatrick, J. Robinson, and A. Frisque, "Wind and tall buildings: Negatives and positives," Structural Design of Tall \& Special Buildings, vol. 17, pp. 915-928, 2008.

[8] J. Salvi and E. Rizzi, "Closed-form optimum tuning formulas for passive tuned mass dampers under benhcmark excitations," Smart Structures \& Systems, vol. 17, pp. 231-256, 2016.

[9] A. Ghosh and B. Basu, "A closed-form optimal tuning criterion for tmd in damped structures," Structural Control \& Health Monitoring, vol. 14, pp. 681-692, 2007.

[10] Y. L. Cheung and W. O. Wong, " $\mathrm{H}_{\infty}$ and $\mathrm{H}_{2}$ optimizations of a dynamic vibration absorber for suppressing vibrations in plates," Journal of Sound \& Vibration, vol. 320, pp. 29-42, 2009.

[11] M. H. Miguélez, L. Rubio, J. A. Loya, and J. Fernández-Sáez, "Improvement of chatter stability in boring operations with passive vibration absorbers," International Journal of Mechanical Sciences, vol. 52, no. 10, pp. 1376-1384, 2010. 
[12] S. Zhu, W.-A. Shen, and Y.-L. Xu, "Linear electromagnetic devices for vibration damping and energy harvesting: Modeling and testing," Engineering Structures, vol. 34, pp. 198-212, 2012.

[13] J. Zhu and W. Zhang, "Coupled analysis of multi-impact energy harvesting from low-frequency wind induced vibrations," Smart Materials and Structures, vol. 24, no. 4, Article ID 045007, 2015.

[14] I. L. Cassidy, J. T. Scruggs, S. Behrens, and H. P. Gavin, "Design and experimental characterization of an electromagnetic transducer for large-scale vibratory energy harvesting applications," Journal of Intelligent Material Systems and Structures, vol. 22, no. 17, pp. 2009-2024, 2011.

[15] W. A. Shen, S. Zhu, and Y. L. Xu, "An experimental study on self-powered vibration control and monitoring system using electromagnetic tmd and wireless sensors," Sensors \& Actuators A Physical, vol. 180, pp. 166-176, 2012.

[16] X. Tang and L. Zuo, "Simultaneous energy harvesting and vibration control of structures with tuned mass dampers," Journal of Intelligent Material Systems \& Structures, vol. 23, pp. 2117-2127, 2012.

[17] L. Zuo and X. Tang, "Large-scale vibration energy harvesting," Journal of Intelligent Material Systems \& Structures, vol. 24, pp. 1405-1430, 2013.

[18] A. Gonzalez-Buelga, L. R. Clare, A. Cammarano, S. A. Neild, S. G. Burrow, and D. J. Inman, "An optimised tuned mass damper/harvester device," Structural Control \& Health Monitoring, vol. 21, pp. 1154-1169, 2014.

[19] S. F. Ali and S. Adhikari, "Energy harvesting dynamic vibration absorbers," Journal of Applied Mechanics, Transactions ASME, vol. 80, no. 4, Article ID 041004, 2013.

[20] A. Gonzalez-Buelga, L. R. Clare, A. Cammarano, S. A. Neild, S. G. Burrow, and D. J. Inman, "An optimised tuned mass damper/harvester device," Structural Control and Health Monitoring, vol. 21, no. 8, pp. 1154-1169, 2014.

[21] C. Madhav and S. F. Ali, "Harvesting energy from vibration absorber under random excitations," IFAC-PapersOnLine, vol. 49, no. 1, pp. 807-812, 2016.

[22] M. C. Smith, "Synthesis of mechanical networks: the inerter," Institute of Electrical and Electronics Engineers. Transactions on Automatic Control, vol. 47, no. 10, pp. 1648-1662, 2002.

[23] M. Z. Q. Chen, C. Papageorgiou, F. Scheibe, F.-C. Wang, and M. Smith, "The missing mechanical circuit element," IEEE Circuits and Systems Magazine, vol. 9, no. 1, pp. 10-26, 2009.

[24] M. C. Smith and F. U.-C. Wang, "Performance benefits in passive vehicle suspensions employing inerters," Vehicle System Dynamics, vol. 42, no. 4, pp. 235-257, 2004.

[25] C. Papageorgiou and M. C. Smith, "Positive real synthesis using matrix inequalities for mechanical networks: Application to vehicle suspension," IEEE Transactions on Control Systems Technology, vol. 14, no. 3, pp. 423-435, 2006.

[26] Y. L. Hu, M. Z. Q. Chen, and Z. Shu, "Passive vehicle suspensions employing inerters with multiple performance requirements," Journal of Sound and Vibration, vol. 333, no. 8, pp. 2212-2225, 2014.

[27] J. Z. Jiang, A. Z. Matamoros-Sanchez, R. M. Goodall, and M. C. Smith, "Passive suspensions incorporating inerters for railway vehicles," Vehicle System Dynamics, vol. 50, no. 1, pp. 263-276, 2012.

[28] F.-C. Wang, M.-K. Liao, B.-H. Liao, W.-J. Su, and H.-A. Chan, "The performance improvements of train suspension systems with mechanical networks employing inerters," Vehicle System Dynamics, vol. 47, no. 7, pp. 805-830, 2009.

[29] K. Ikago, K. Saito, and N. Inoue, "Seismic control of singledegree-of-freedom structure using tuned viscous mass damper," Earthquake Engineering \& Structural Dynamics, vol. 41, pp. 453474, 2012.

[30] Y. Nakamura, A. Fukukita, K. Tamura et al., "Seismic response control using electromagnetic inertial mass dampers," Earthquake Engineering \& Structural Dynamics, vol. 43, pp. 507-527, 2014.

[31] R. Mirza Hessabi and O. Mercan, "Investigations of the application of gyro-mass dampers with various types of supplemental dampers for vibration control of building structures," Engineering Structures, vol. 126, pp. 174-186, 2016.

[32] M. Saitoh, "On the performance of gyro-mass devices for displacement mitigation in base isolation systems," Structural Control and Health Monitoring, vol. 19, no. 2, pp. 246-259, 2012.

[33] I. F. Lazar, S. A. Neild, and D. J. Wagg, "Using an inerterbased device for structural vibration suppression," Earthquake Engineering \& Structural Dynamics, vol. 43, pp. 1129-1147, 2014.

[34] I. F. Lazar, S. A. Neild, and D. J. Wagg, "Vibration suppression of cables using tuned inerter dampers," Engineering Structures, vol. 122, pp. 62-71, 2016.

[35] L. Marian and A. Giaralis, "Optimal design of a novel tuned mass-damper-inerter (TMDI) passive vibration control configuration for stochastically support-excited structural systems," Probabilistic Engineering Mechanics, vol. 38, pp. 156-164, 2014.

[36] J. Salvi and A. Giaralis, "Concept study of a novel energy harvesting-enabled tuned mass-damper-inerter (eh-tmdi) device for vibration control of harmonically-excited structures," Journal of Physics: Conference Series, vol. 744, Article ID 012082, 2016.

[37] T. Asami, Optimal design of double-mass dynamic vibration absorbers arranged in series or in parallel, 2016.

[38] Y. Liu, C.-C. Lin, J. Parker, and L. Zuo, "Exact H2 Optimal Tuning and Experimental Verification of Energy-Harvesting Series Electromagnetic Tuned-Mass Dampers," Journal of Vibration and Acoustics, Transactions of the ASME, vol. 138, no. 6, Article ID 061003, 2016.

[39] E. Lefeuvre, D. Audigier, C. Richard, and D. Guyomar, "Buckboost converter for sensorless power optimization of piezoelectric energy harvester," IEEE Transactions on Power Electronics, vol. 22, no. 5, pp. 2018-2025, 2007.

[40] I. Gradshteyn and I. Ryzhik, Table of Integrals Series and Product, Academic Press, 1980.

[41] T. Asami, O. Nishihara, and A. M. Baz, "Analytical solutions to $\mathrm{h}_{8}$ and $\mathrm{h}_{2}$ optimization of dynamic vibration absorbers attached to damped linear systems," Journal of Vibration \& Acoustics, p. 124, 2002.

[42] Y. Liu, L. Zuo, C.-C. Lin, and J. Parker, "Exact H2 optimal tuning and experimental verification of energy harvesting series electromagnetic tuned mass dampers," in Proceedings of Active and Passive Smart Structures and Integrated Systems 2016, March 2016.

[43] T. Haskett, B. Breukelman, J. Robinson, and J. Kottelenberg, Tuned mass dampers under excessive structural excitation, 2003.

[44] A. G. Davenport, “Gust loading factors," Journal of the Structural Division, vol. 93, pp. 11-34, 1967. 
[45] N. Chen, Y. Li, and H. Xiang, "A new simulation algorithm of multivariate short-term stochastic wind velocity field based on inverse fast Fourier transform," Engineering Structures, vol. 80, pp. 251-259, 2014.

[46] D. C. K. Poon, S. Shieh, L. M. Joseph, and C. Chang, "Structural design of taipei 101, the world's tallest building," in Proceedings of the CTBUH 2004 Seoul Conference, 2004. 


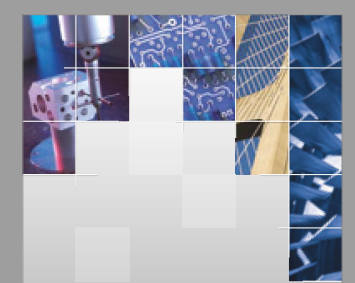

\section{Enfincering}
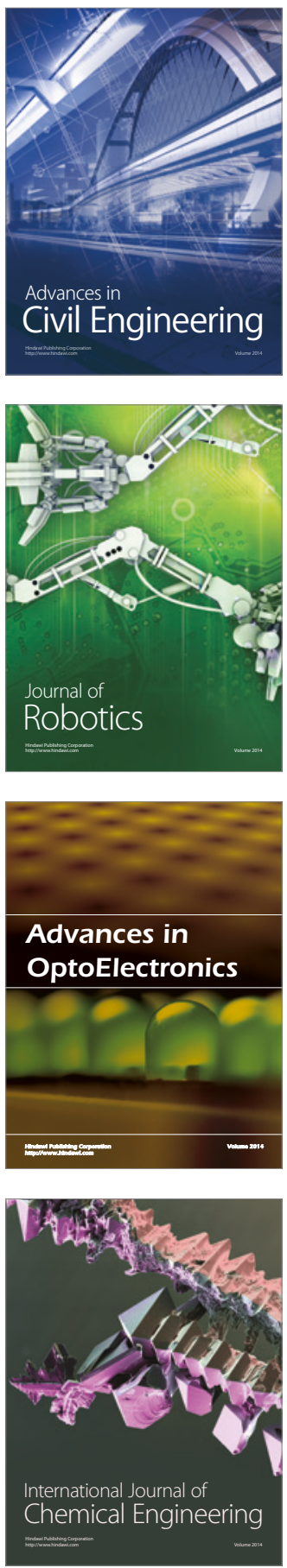

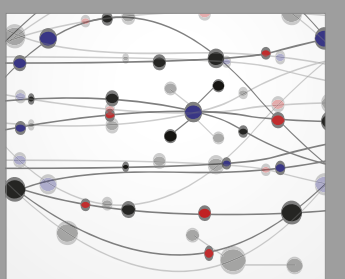

The Scientific World Journal

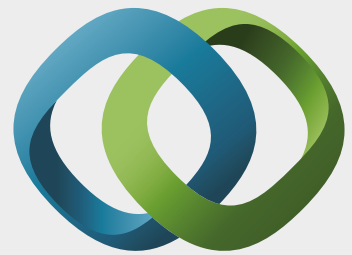

\section{Hindawi}

Submit your manuscripts at

https://www.hindawi.com
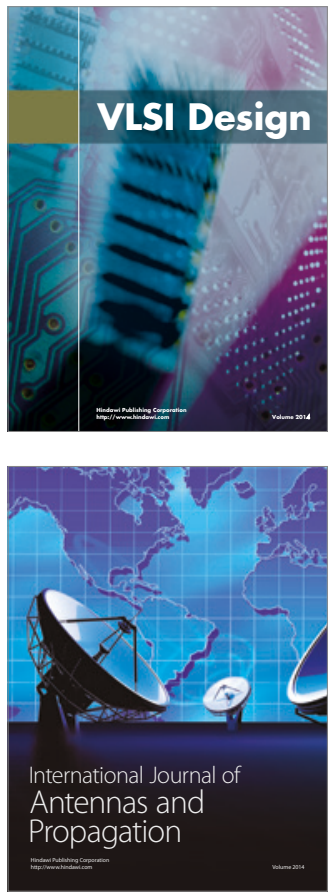

\section{Rotating}

Machinery
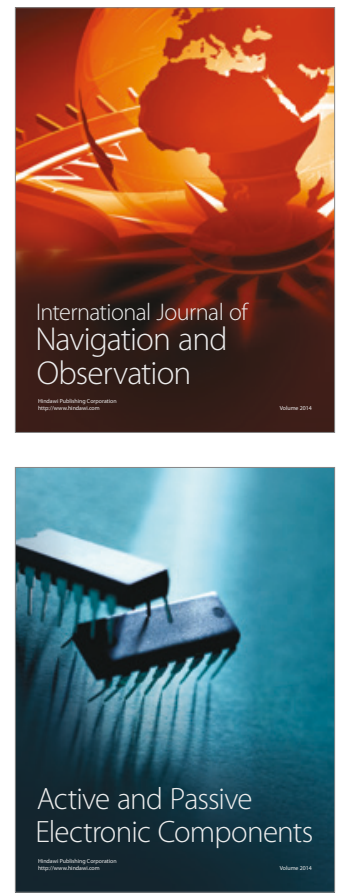
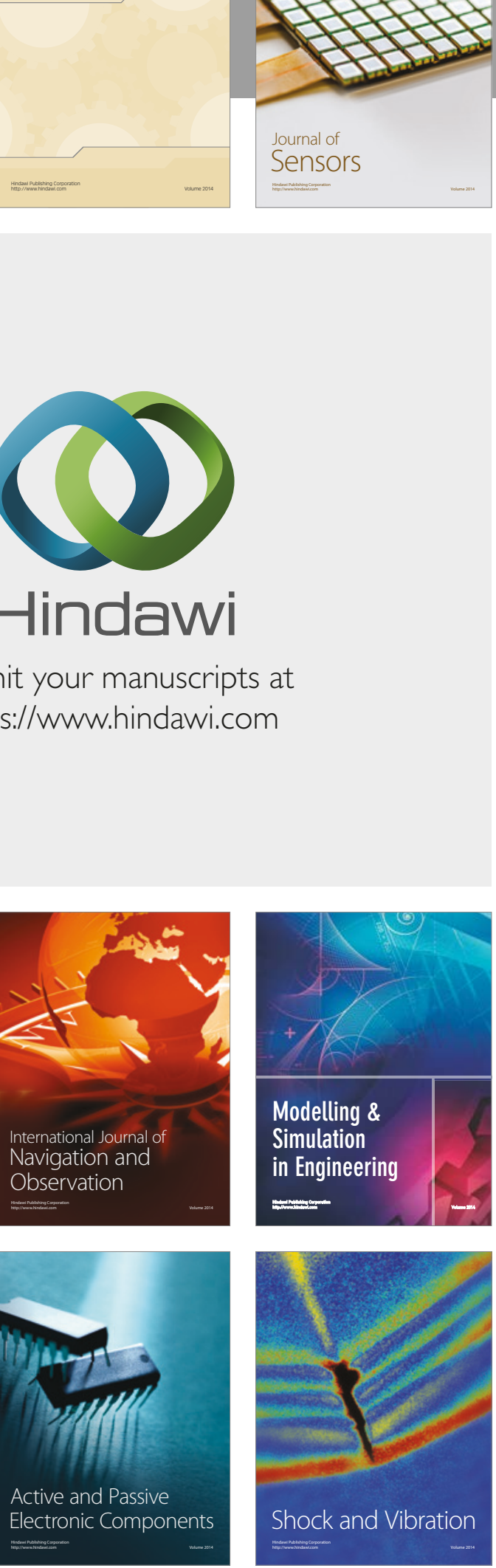
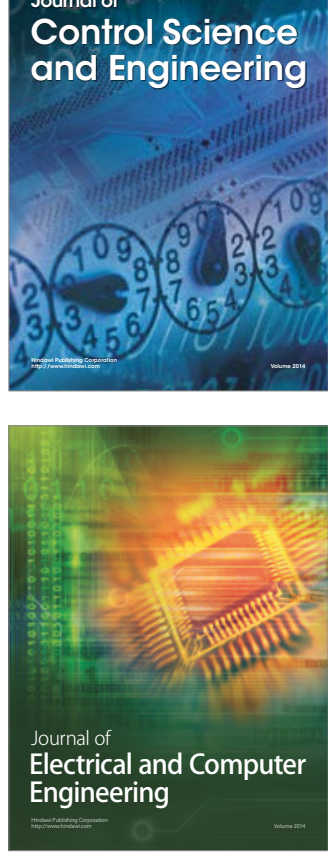

Distributed

Journal of

Control Science

and Engineering
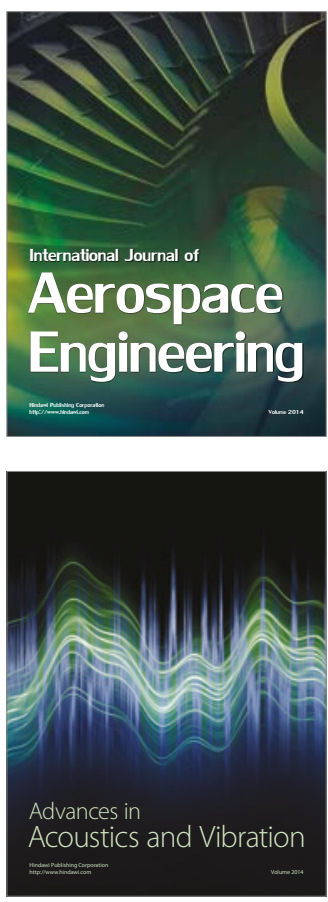

Sensor Networks 